\title{
Starting Well Programme launched in Middlesbrough
}

On 17 October, Durham, Darlington and Tees Local Dental Network in collaboration with Middlesbrough Local Authority launched the Middlesbrough Starting Well Programme.

This national programme, implemented locally, aims to improve oral health and increase dental attendance of 0-5-year-old children. Nationally, 13 areas with the worst oral health have been targeted with additional resources from NHS England to improve oral health outcomes.

The programme will involve dental practices implementing a prevention pathway for 0-5-year-old children, audit and also community outreach activities to promote and encourage dental attendance by the age of one.

The launch event was opened by Dr James Gossow, Assistant Medical Director NHS England Cumbria and the North East, followed by presentations from the Office of the Chief Dental Officer: Melanie Catleugh; Kamini Shah, Public Health England; and the
Middlesbrough Director of Public Health, Edward Kunonga.

The second half of the evening included participant workshops to identify how partnership working between dental practices and health visiting and other public health teams could improve access for our youngest and most vulnerable children.

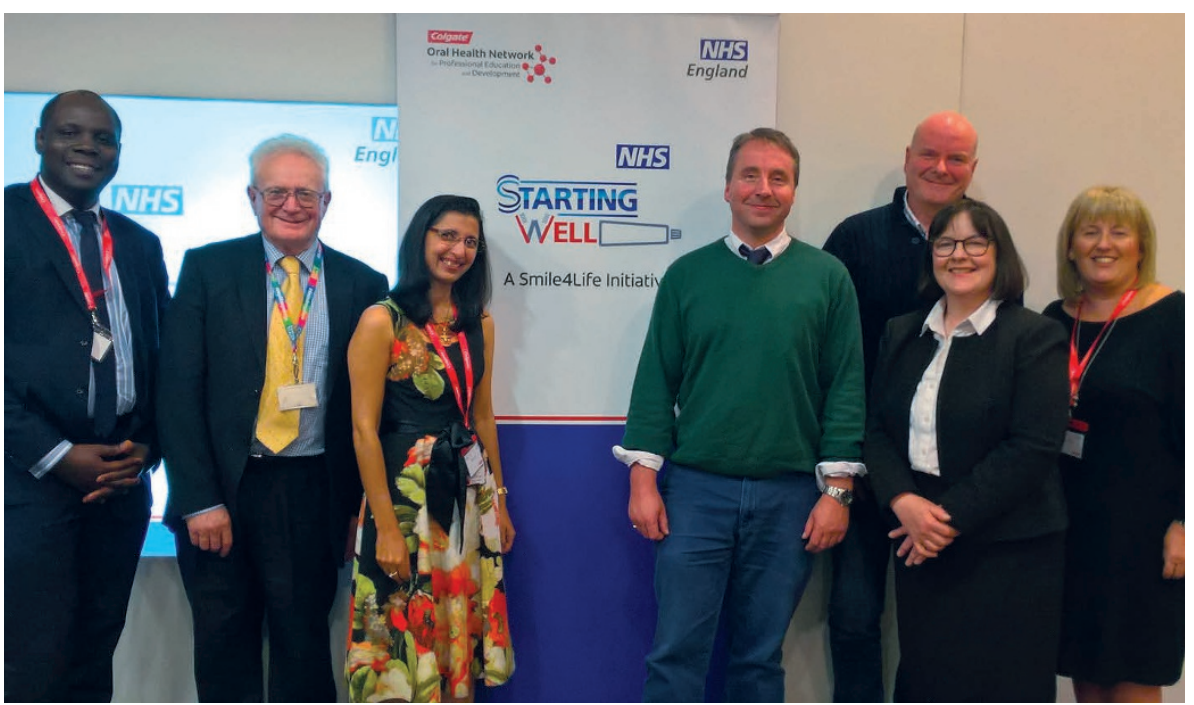

(I-r) Edward Kunonga (Middlesbrough Director of Public Health), Malcolm Smith (Postgraduate Dental Dean), Kamini Shah (Consultant in Dental Public Health), James Gossow (Assistant Medical Director), Tom Robson (Chair, Durham, Darlington \& Tees Local Dental Network), Melanie Catleugh (Clinical Adviser, OCDO) and Pauline Fletcher (Primary Care Commissioning Manager)

\section{BOOK REVIEW}

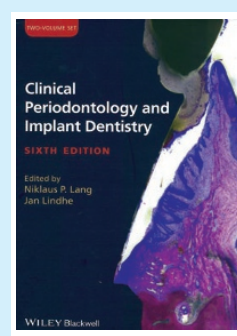

CLINICAL PERIODONTOLOGY AND IMPLANT DENTISTRY, 2-VOLUME SET, 6TH EDITION

Niklaus P. Lang and Jan Lindhe

2015, Wiley-Blackwell

price $£ 199.99$ pp. 1480

ISBN: 9780470672488

This book covers periodontology and the perio-implant interface, which includes the concept of how periodontology affects the biology of implants. The book has expanded its scope since the first edition, published in 1997. This revised and updated edition is evidence based written by internationally recognised researchers and master clinicians from all over the world.

Volume 1 focuses on 'basic topics': anatomy, physiology and pathology, while Volume 2 focuses more on 'clinical concepts'. The terminology in this book is very straightforward and the text provides extensive detail in each topic covered. Also, the many clinical photographs, radiographs and charts make this book quite accessible. Readers will be relieved to know that this book is structured in a very organised, easy-to-use format, allowing topics to be found quite quickly from the contents. However, I would recommend the eBook as this makes the book more portable.

The book is quite extensive in its content. It covers all areas of periodontology with a specific focus on perio-implant considerations. It would be a great tool to have in the early years of undergraduate dentistry and would continue to be of great use right through dental school to final year. This one edition covers the entire undergrad syllabus (and then some!). I also think it would be useful to have the same book for studying periodontology, I feel it would tie things up quite well and would give the student an overall better all-round knowledge of periodontology. Volumes 1 and 2 combine to knit the theory quite well with the clinical, which can often be poorly understood by students.

However, this book definitely covers more than just the undergraduate syllabus. Volume 1 includes anatomy, physiology and pathology relating to implants beyond the scope of undergraduates. Volume 2 includes the clinical aspects of implant placement and periodontal considerations. There are specific chapters relating to bone augmentation, sinus lifts, orthodontic considerations relating to perio and implants, restoring implants and concepts of tissue integration. It addresses biological complications that occur in implants and coping with adverse events.

As a dentist in general practice, I found the series quite useful for quick referencing. Overall, this book would be an invaluable resource throughout a dentist's career. It provides a wealth of information useful to undergraduates, dentists and specialists who want to fine tune their knowledge base in up-to-date, well-researched periodontology and implantology.

\section{S. Brosnan} Available to buy from the BDA shop: https://shop.bda.org 